\title{
Blutiges Erwachen nach durchfeierter Nacht
}

Scherben, zertrümmerte Möbel, überall Blut: Eine 16-jährige wacht im vollkommen verwüsteten Haus ihrer Eltern mit schwerwiegenden Stich- und Schnittverletzungen auf. Sie erinnert sich an nichts.

Was ist geschehen?

Von einem sehr drastischen Fall berichtete Dr. Katja Jachau, Institut für Rechtsmedizin, Magdeburg, auf der 94. Jahrestagung der Deutschen Gesellschaft für Rechtsmedizin: Eine Jugendliche wachte am späten Mittag in einer Blutlache auf, ohne sich an die Geschehnisse der letzten Nacht zu erinnern. Es ließ sich rekonstruieren, dass zwei Freundinnen die 16-Jährige nach einem gemeinsamen Diskobesuch in den frühen Morgenstunden nach Hause gebracht hatten. Die Eltern befanden sich im Urlaub.

Als die Jugendliche erwachte, rief sie bei ihrer Freundin an, die den Notarzt verständigte. In der Notaufnahme wurden tiefe Schnitt- und Stichverletzungen festgestellt - unter anderem eine glattrandige Durchtrennung des Oberschenkelmuskels. Auch an der Körperrückseite fanden sich oberflächliche Schnittspuren. Zusätzlich fand sich in Nähe des Genitalbereichs eine Schnittwunde, so dass der Verdacht des sexuellen Missbrauchs nahelag. Doch die daraufhin angesetzte gynäkologische Untersuchung ergab keinen derartigen Befund.

Auffälligkeiten hingegen gab es in der Blutprobe der Jugendlichen, die auf Nachfrage der zugezogenen Rechtsmedizinerin erfolgte: Eine AmphetaminKonzentration von $61 \mathrm{ng} / \mathrm{ml}$ und eine MDMA-Konzentration von $840 \mathrm{ng} / \mathrm{ml}$.

\section{Straftat oder Sellbstverletzung?}

In einer Befragung gestand die 16-Jährige, dass sie im Laufe des Abends neun Tabletten unbekannten Inhalts zu sich genommen habe. Als Begründung dafür gab sie an, dass der Alkohol in der Disko zu teuer gewesen sei. Ihre Angabe, dass sie zuvor noch nie illegale Drogen konsumiert habe, ließ sich nicht überprüfen.
In der Altbauwohnung der Eltern konnten Messer, reichlich Scherben und Blutspuren sichergestellt werden, aber es fanden sich keinerlei Hinweise auf eine Fremdeinwirkung. Daher ist im vorliegenden Fall davon auszugehen, dass die Beschädigte sich die lebensbedrohlichen
Verletzungen im Drogenrausch selbst zugefügt hat. Die Wirkung von Amphetaminen auf die Psyche kann verheerend sein: Visuelle und akustische Halluzinationen sind keine Seltenheit.

Auch wenn am Anfang der Eindruck einer Straftat nahelag, schloss Jachau ihren Vortrag mit folgendem Fazit: „Nicht jeder Tatort ist ein Tatort“.

(Regina Kilchenstein)

94. Jahrestagung der Deutschen Gesellschaft für Rechtsmedizin 15.-19.09.2015 in Leipzig, Vortrag: "Straftat, Amphetamine, Selbstverletzung-Wer bedingt wen?"

\section{Babytransporter nicht zweckentfremden! Todesfalle Kindersitz}

Für Kinder unter zwei Jahren können Sitze und andere Transportmittel zur Todesfalle werden, wenn die Kleinen über längere Zeit unbeaufsichtigt bleiben.

Schlafprobleme von Kleinkindern lassen Eltern erfinderisch werden. Doch wie eine US-Studie gezeigt hat, können Experimente mit verschiedenen Sitz- und Liegekonstruktionen lebensbedrohlich sein, wenn sie über ihren eigentlichen Zweck hinaus eingesetzt werden. Erich Batra und Kollegen haben den Tod von 47 Kindern, zwei Jahre oder jünger, untersucht, die zwischen 2004 und 2008 beim Liegen oder Sitzen zu Tode gekommen waren.

31 der Kinder verstarben in einem Autositz, die anderen in Tragetüchern, Babywippen und -schaukeln sowie im Kinderwagen. Bei den Kindern in den Autositzen lagen zwischen dem letzten Kontakt zum lebenden Kind und der Feststellung des Todes zwischen vier Minuten und elfStunden. Es gab also Kinder, die ganze Nächte ohne Elternkontakt in einem Autositz verbracht hatten. Und sie waren größtenteils nicht auf Reisen. Von 18 der 31 Kinder war bekannt, an welchem Ort sie sich zum Zeitpunkt ihres Todes befunden hatten: Bei 13 stand der Autositz im Haus, bei drei in der Tagesbetreuung, und nur zwei der Kinder kamen im Auto ums Leben.

\section{Kinder nicht unbeaufsichtigt lassen} Bis auf eine Ausnahme wurde als Todesursache „Ersticken“ festgestellt. Jedes zweite Kind, das im Autositz starb, strangulierte sich an einem Gurt. Die anderen erlitten einen lagebedingten Erstickungstod. Die Ergebnisse zeigten, so Batra und Kollegen, dass Kinder bis zu zwei Jahren in Sitz- und Tragevorrichtungen weder im Wachzustand noch im Schlaf unbeaufsichtigt sein sollten. Auf keinen Fall sollten Kinder in Autositzen außerhalb des Autos schlafen und im Auto sollten sie niemals abgeschnallt oder nur teilweise angeschnallt sein. Die meisten Todesfälle hätten durch eine sachgerechte Nutzung der Sitze und ausreichende Betreuung verhindert werden können, so die Autoren. (ChristineStarostzik)

Batra EK et al. JPEDS 2015 (online first) 